\title{
UTERINE RUPTURE DURING EXTRADURAL BLOCKADE
}

\author{
Karl-Ludwig Eckstein, M.D., Samuel G. Oberlander, M.D., and \\ GerTIE F. MARX, M.D.*
}

\begin{abstract}
PaIN of the first stage of labour is abolished by sensory blockade of the tenth thoracic through first lumbar segments. ${ }^{1}$ The development of pain subsequent to adequate relief during continuous lumbar extradural block is usually caused by tachyphylaxis to the local anaesthetic drug ${ }^{2,3}$ or by displacement of the needle or catheter. ${ }^{4}$ However, pain may also result from an obstetric complication such as a ruptured uterus as described in the following case report.
\end{abstract}

\section{Case Report}

A 23-year-old para 2-0-0-2 was admitted in active labour. Her first child had been delivered vaginally without complications. Her second pregnancy was terminated by Caesarean section because of placenta praevia. Since the section was of the lower segment type and had healed uneventfully, vaginal delivery was planned for this third pregnancy.

At $6 \mathrm{~cm}$ dilatation of the cervix, a lumbar extradural block was instituted. The catheter was introduced cephalad through a 16-gauge Tuohy needle inserted in the third lumbar interspace. Injection of $10 \mathrm{ml}$ of 2 per cent chloroprocaine (Nesacaine) resulted in a sensory block extending from the ninth thoracic through the third lumbar segment and complete relief of pain. The block was reinforced 30 minutes later with $6 \mathrm{ml}$ of the same solution, and pain relief remained satisfactory. Approximately 15 minutes later, the patient became restless and began to complain of diffuse abdominal pain which was exaggerated during uterine contractions. Her vital signs were unchanged. Despite repositioning of the catheter and two additional injections of $8 \mathrm{ml}$ each of chloroprocaine, she continued to experience pain although there appeared to be absence of sensation to pinprick. Labour progressed rapidly. Shortly after the cervix became fully dilated, the foetal heart rate slowed repeatedly, and a mid-forceps extraction was performed under nitrous oxide $(4 \mathrm{~L})$ oxygen $(6 \mathrm{~L})$ analgesia. The newborn infant was normal with one-minute Apgar score of " 6 " and five-minute score of “9." The placenta was delivered spontaneously without difficulty. However, the patient became hypotensive and unresponsive. Exploration of the uterus revealed a defect in the old uterine incision. Because of the hypotension, immediate laparotomy was undertaken under endotracheal nitrous oxide (5 L) oxygen (3

"From the Departments of Anaesthesiology and Obstetrics and Gynaecology of the Albert Einstein College of Medicine, Bronx, New York.

Mail correspondence to: Gertie F. Marx, M.D., Department of Anaesthesiology, Albert Einstein College of Medicine, 1300 Morris Park Avenue, Bronx, New York 10461. 
L)-succinylcholine anaesthesia and confirmed rupture of the uterine scar on the left into the retroperitoneal space; the bladder was intact and there was no intraperitoneal bleeding. The defect was repaired, and the patient made an uneventful recovery.

\section{Discussion}

When the indication for a previous abdominal delivery, such as foetal-pelvic disproportion, still exists, repeated Caesarean section is the procedure of choice. If, however, the original indication is no longer present, subsequent vaginal delivery is now permitted with increasing frequency, provided that the section was of the lower segment type and that wound healing was uncomplicated. The probability of rupture of a lower segment scar is three to four times less than with a classical incision. In 624 pregnancies subsequent to Caesarean section managed at the Johns Hopkins Hospital between 1900 and 1942, the incidence of rupture was 2.1 per cent; most of these sections were of the classical type. In a more recent survey at the same hospital, in 699 pregnancies following Caesarian section, mostly of the lower segment type, rupture occurred in only 0.5 per cent. ${ }^{5}$

Uterine ruptures may be classified as complete and incomplete. In complete rupture the peritoneal cavity is opened. In the incomplete rupture the muscle is torn but the peritoneum remains intact although a subperitoneal haematoma usually develops. Complete ruptures are sudden, explosive, and almost always associated with severe pain and shock. Incomplete ruptures are gradual in development; the pain is less intense and is coupled with abdominal tenderness rather than collapse. If blood distends a broad ligament, pain is felt down the leg. If the blood is exuded into the peritoneal cavity, it may seep under the diaphragm and cause referred pain in the shoulders. ${ }^{6}$ Pain resulting from uterine rupture resembles that associated with perforation of the bladder during transurethral surgery. When perforation occurs, the urological patient under regional analgesia experiences sudden abdominal pain which may be diffuse or localized in the para-umbilical, suprapubic or epigastric region; occasionally, the pain is referred to the shoulder or precordium. ${ }^{7}$ It has been stated that "the anesthesiologist can be of aid to the urologist in the diagnosis of a rupture of the bladder or vesical neck during transurethral resection." 8 Similarly, the anaesthetist may be the first physician of the team to diagnose uterine rupture provided that unusual pain is recognized as a symptom of an obstetrical complication rather than as failure of the extradural block.

\section{SUMMARY}

A multiparous woman, permitted to deliver vaginally two years after a Caesarean section, had complete relief of the pain of the first stage of labour provided by continuous lumbar extradural block for over one hour. When she began to experience diffuse abdominal pain, more local anaesthetic was injected and the catheter was repositioned. However, the pain persisted. Following delivery of the infant, incomplete rupture of the uterus was discovered. 
When pain develops unexpectedly during successful extradural analgesia, it may be indicative of an obstetrical complication rather than of a "failed" block. Awareness of this eventuality may provide for early diagnosis of complications.

\section{RÉSUMÉ}

Une multipare fut permise de délivrer par voie vaginale deux ans après une césarienne. Elle n'eu aucune douleur pendant plus d'une heure après avoir reçu une analgésie épidurale lombaire continue. Elle commença à sentir une douleur abdominale diffuse; deux nouvelles doses d'anesthésie locale furent injectées et le cathéter fut replacé. La douleur, cependant, ne diminua pas. Après la naissance de l'enfant, une rupture incomplète de la matrice fut découverte.

Quand la douleur réapparait soudainement durant une analgésie épidurale parfaite, elle peut traduire une indication d'une complication obstétricale plutôt qu'un échec de l'anésthesie épidurale. La reconnaissance de cette eventualité peut servir à établir le diagnostic d'une complication.

\section{REFERENCES}

1. Bonica, J.J. Obstetric analgesia and anesthesia. Springer Verlag, Berlin, Heidelberg, New York. pp. 49-51 (1972).

2. Bromage, P.R. Physiology and pharmacology of epidural analgesia. Anesthesiology 28: 592 (1967).

3. DE Jong, R.H. Physiology and pharmacology of local anesthesia. C.C. Thomas, Springfield. pp. 131-132 (1970).

4. Adriani, J. Labat's Regional Anesthesia, 3rd ed. W.B. Saunders Co., Philadelphia and London. p. 308 (1967).

5. Eastman, N.J. \& Hellman, L.M. Williams Obstetrics, 12th ed. Appleton-CenturyCrofts, New York. pp. 981-986 (1961).

6. Greenhill, J.P. Obstetrics, 12th ed. W.B. Saunders Co., Philadelphia and London. pp. 780-788 (1961).

7. KENYON, H.R. Perforation in transurethral operations; technic for immediate diagnosis and management of extravasations. J.A.M.A. 142: 798 (1950).

8. Simpson, R.A. Rupture of bladder during transurethral resection of prostate and possibility of aid by anesthesiologist in its diagnosis. Urol. Cutan. Rev. 50: 628 (1946). 